\title{
Growth and subsidence of carbonate platforms: numerical modelling and application to the Dolomites, Italy
}

\author{
Claudia Marella $\left({ }^{1}\right)$, Riccardo Caputo $\left({ }^{2}\right)$ and Alfonso Bosellini $\left({ }^{3}\right)$ \\ (') Dipartimento di Scienze della Terra, Università degli Studi di Camerino, Italy \\ (') DiSGG, Università degli Studi della Basilicata, Potenza, Italy \\ ${ }^{3}{ }^{3}$ Dipartimento di Scienze della Terra, Università degli Studi Ferrara, Italy
}

\begin{abstract}
The phenomenon of subsidence induced by the growth of carbonate platforms has been investigated with the aid of numerical modelling. The research aimed to quantify the relative contribution of this process in the creation of the accommodation space required to pile up thick neritic bodies. We analysed two end-member deformation styles, namely the elastic behaviour of the lithosphere when locally loaded and the plastic-like reaction of a sedimentary succession underlying a growing carbonate buildup. The former process, analysed using a modified flexural model, generates a regional subsidence. In contrast, the latter process, simulated by considering the compaction occurring in soft sediments, generates a local subsidence. We attempted to quantify the amount and distribution of subsidence occurring below and surrounding an isolated platform and in the adjacent basin. The major parameters playing a role in the process are discussed in detail. The model is then applied to the Late Anisian-Early Ladinian generation of carbonate platforms of the Dolomites, Northern Italy, where they are spectacularly exposed. Taking also into account the Tertiary shortening that occurred in the area, both local and regional subsidence contributions of major platform bodies have been calculated aimed at a reconstruction of the map of the induced subsidence. A major outcome of this study is that the accommodation space, that allowed the accumulation of very thick shallow-water carbonate successions in the Dolomites, was only partially due to lithospheric stretching while the contribution given by the 'local' overload is as high as $20-40 \%$ of the total subsidence. Our results also shed some light on the water-depth problem of the Triassic basins as well as on the basin-depth to platform-thickness relationships.
\end{abstract}

Key words lithospheric flexure-differential compaction - Triassic

\section{Introduction}

The peculiarity of carbonate platforms is that sediments can be produced only in a few meters of water depth. This notwithstanding, in many

Mailing address: Prof. Riccardo Caputo, DiSGG, Università degli Studi della Basilicata, C.da Macchia Romana, 85100 Potenza, Italy; e-mail: rcaputo@unibas.it regions of the world both past and present platforms commonly consist of several hundred meters of continuous successions of shallow-water sediments and these thick accumulations can be explained only if accommodation space is continuously created, that is if subsidence of the underlying 'substratum' and/or sea level rise continuously occurs for relatively long time spans.

As concerns sea level variations, nowadays we have a widely accepted knowledge of the first-order global fluctuations scale (Haq et al., 1987) and therefore, for almost any geological time interval we can grossly quantify the contribution of this phenomenon in producing accommodation space. Whatever the case, be- 
cause eustatic curves commonly show some tens of meters of continuous sea-level rise and, just in a few cases, up to $100-150 \mathrm{~m}$, at a first glance this natural phenomenon cannot explain, at least alone, the growth of thick platforms that occurred during many geological periods.

As a consequence, subsidence of the underlying substratum must be claimed as the principal mechanism for the generation of accommodation space during the build up of these sedimentary bodies.

Subsidence of the Earth surface can basically occur as a consequence of three major processes. Firstly, if the lithosphere is horizontally stretched, it becomes thinner (e.g., McKenzie, 1978), the top and bottom interfaces become closer due to the occurrence of a largescale pure shear and thus the Earth surface subsides. This process is mainly referred to as tectonic subsidence and typically occurs during a rifting stage.

Secondly, if the crust and/or the lithosphere become denser, a new lithostatic equilibrium must be reached. A typical example of this process is the thermal subsidence associated with the cooling of the lithosphere in passive margins (Sclater et al., 1971).

Thirdly, if the crust is locally overloaded, again new lithostatic conditions are required to keep the equilibrium. Depending on the rheologic and mechanical behaviour of rocks, this process can induce 'local' subsidence at the scale of the applied load as well as regional effects at distances several times the size of the loaded area. This last case commonly occurs in regions where important topographic structures like volcanoes and oceanic islands can be generated on top of the Earth surface in relatively short time intervals. Typical examples are the fore-deep basins associated with the mountain chains and the post-glacial rebound of Scandinavia.

In this paper the subsidence induced in the lithosphere and within the uppermost crust by the growth of isolated carbonate platforms is investigated. One of the principal aims of this research is estimating the amount and the distribution of subsidence during the growth of a carbonate platform. To achieve this goal we set up a numerical model compiled with the Matlab software. In order to evaluate the role played by the parameters considered, we performed several tests.

A second important aim of this study is the application of the model to the carbonate platforms that grew in the Dolomites, Northern Italy, during Middle Triassic that represent a spectacular and world famous example of carbonate build-ups. As a major outcome, we can tentatively quantify the amount of subsidence induced by the platforms' load and its distribution in the palaeo-Dolomites region. Based on the thickness of the neritic successions and considering the calculated pattern of the 'nearfield' contribution, the amount of subsidence induced by a 'far-field' process can be easily obtained. According to the Middle Triassic geodynamics of the area, the tectonically induced subsidence can be roughly estimated and consequently we can have some idea on the amount of stretching which occurred during that time interval.

\section{The numerical model}

In order for subsidence to occur, the lithosphere and/or the crust must deform either locally or regionally. The deformation process can occur according to three end-member behaviours of lithospheric rocks: elastic, plastic and viscous.

To estimate the subsidence induced by the growth of carbonate platforms two effects have been considered. Firstly, the flexure of a thin elastic plate and, secondly, the plastic deformation due to compaction of the underlying stratigraphic successions progressively buried.

As a first approach, we did not consider the possible contribution associated with a viscous behaviour because important effects in terms of amount of deformation are negligible in relatively short time spans, say of the order of a few million years (e.g., Ranalli, 1987).

The elastic behaviour of the lithosphere has already been recognised in several geodynamic conditions. Classical examples are the flexure induced by the Hawaiian Islands chain (Turcotte and Schubert, 1982), the bending occurring in front of oceanic trenches along subduc- 
tion zones (Karner and Watts, 1983; Wang, 2001) or the deflection associated with continental sedimentary basins (e.g. Walcott, 1970).

The elastic deformation is analysed here using a flexural model of bending lithosphere supported by a denser substratum. The permanent volume reduction occurring in the sedimentary succession, which is progressively buried under the increasing load of a growing carbonate platform, has been considered and consequently modelled as a plastic deformation. The two independent deformational processes are then summed up to calculate the induced subsidence.

\subsection{Flexural model}

The flexure of the lithosphere can be analysed considering the bending of an isotropic elastic plate of thickness $h$, much smaller than the two horizontal dimensions, subjected to a surface load located at the top and supported by a denser substratum (fig. 1). In such conditions, three forces are involved: firstly, the downward facing force exerted by the surface load; secondly, the elastic force generated by the plate resisting bending; thirdly, the buoyant force due to the replacement of dense asthenosphere rocks with less dense lithosphere rocks. Considering the three forces acting on the plate, the general equation describing the deflection in the $x y$ plane is (e.g., Timoshenko and Goodier, 1951)
$D\left\{\frac{\partial^{4} w}{\partial x^{4}}+2 \frac{\partial^{4} w}{\partial x^{2} \partial y^{2}}+\frac{\partial^{4} w}{\partial y^{4}}\right\}+\left(\rho_{m}-\rho_{i}\right) g w=L$

where $g$ is the gravity acceleration, $\rho_{m}$ the density of the asthenosphere, $\rho_{i}$ the density of the replacing materials (sediments and water), $L$ is the linear surface load and $w$ is the deflection of the plate relative to the centre of load application. $D$ represents the flexural rigidity that is equal to $T_{e}^{3} E / 12\left(1-v^{2}\right)$, where $T_{e}$ is the elastic thickness, $E$ is the Young modulus and $v$ is the Poisson coefficient.

This equation can be applied to linear topographic features like mountain ranges or aligned oceanic islands. Indeed, in this case, where the bending geometry is the same in any cross-section normal to the long dimension of the loading body the problem is reduced to a one-dimensional elastic bending

$$
D \frac{d^{4} w}{d x^{4}}+\left(\rho_{m}-\rho_{i}\right) g w=L
$$

For a linear load along the $y$ axis at $x=0$ the general solution is (Turcotte and Schubert, 1982)

$$
w_{x}=w_{0} e^{-x / \alpha}\left(\cos \frac{x}{\alpha}+\sin \frac{x}{\alpha}\right)
$$

where $w_{\mathrm{x}}$ is the deflection at a distance $x$ from the load, $w_{0}$ is the maximum deflection at $x=0$ given by

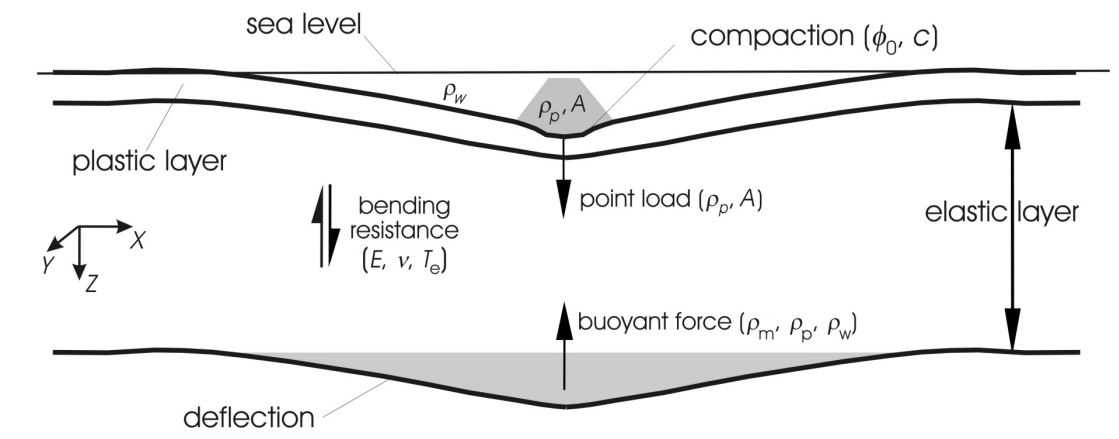

Fig. 1. Simplified sketch of the numerical model used to estimate the subsidence induced by the growth of a carbonate platform: deflection and compaction processes occurring within the elastic and plastic layers, respectively, are indicated along with the main parameters. $E$ : Young modulus; $v$ : Poisson coefficient; $T_{e}$ : equivalent elastic thickness; $\rho_{w}$ : water density; $\rho_{p}$ : platform rock density; $A$ : platform dimensions; $\rho_{m}$ : mantle density. 


$$
w_{0}=L \alpha^{3} / 8 D
$$

and $\alpha$ is the flexural parameter $\alpha=\left[4 D /\left(\rho_{m}+\right.\right.$ $\left.\left.-\rho_{i}\right) g\right]^{1 / 4}$.

Keeping in mind that the aim of this study is to estimate the flexure of the lithosphere caused by a point load as a carbonate platform (bidimensional case), we also need to consider the shear stress induced in the $y z$-plane that obviously plays an important role in reducing the maximum subsidence. According to Lowrie (1997), because a load with equal horizontal dimensions causes a central depression that is less than a quarter the effect of the linear load a corrective coefficient is introduced in eq. (2.3), which thus becomes

$$
w=0.25\left[w_{0} e^{-r / \alpha}\left(\cos \frac{r}{\alpha}+\sin \frac{r}{\alpha}\right)\right]
$$

where $r$ is the radial distance from the point load. We are well aware that this coefficient is an oversimplification of the mathematical aspects and it does not correspond to a rigorous solution of the differential equation. Nevertheless, we prefer to keep the mathematics to a minimum for several reasons. Firstly, because the principal aim of the paper is to assess the order of magnitude of this natural phenomenon and not to quantify it exactly. Secondly, the values that some of the parameters included in the above equations can assume within their possible ranges induce an even larger variability in the results. Accordingly, eq. (2.5) has been used to estimate as a first attempt the amount of lithospheric flexure due to the growth of a carbonate platform.

\subsection{Compaction model}

The plastic deformation is estimated by applying a compaction model. The thickness reduction of the sedimentary successions, buried under an increasing load has been calculated. The compaction in sedimentary units commonly occurs due to the leakage of pore fluids and to a general geometric reorganisation of the particles consisting in the partial collapse of the grain framework, plastic deformation of soft fragments, and fracturing and pressure solution phenomena (Rieke and Chilingarian, 1974). At greater depths even mineralogical transformations can contribute to a progressive volume (i.e. thickness) reduction. All these factors lead to a reduction in porosity. Another important factor that influences the porosity reduction is the precipitation of cement material, though this process is more an obstacle to the compaction process.

If analysed in detail, diagenetic compaction of sediments is not a simple plastic deformation mechanism, but for the purposes of this research and particularly at the scale we consider, as a first approximation this natural process can be modelled as a plastic deformation (fig. 1).

The mechanical compaction of sediments depends on the buried depth (i.e. lithostatic load) and on the differential stresses. If the compaction is the only working process, the thickness of the solid component remains constant and therefore the ratio between solidity $(1-\phi)$ and the thickness reduction is linear (Baldwin and Butler, 1985). In this study we use a simple porosity-depth function as proposed by Athy (1930). Ruby and Hubert (1960) showed that the porosity should be an exponential function of depth in the form

$$
\phi=\phi_{0} e^{-c z}
$$

where $\phi_{0}$ is the initial porosity and $c$ is the compaction factor.

In this study we follow the approach proposed by Sclater and Christie (1980), which allows estimation of the depositional (i.e. original) thickness of a sedimentary succession from the present-day thickness as directly measured in the field. For example, if we assume a total overburden thickness that caused a certain compaction, inversion of eq. (2.6) allows to 'de-compact' the deposits. Accordingly, we can calculate the thickness for any depth of burial and from the difference between this calculated value and the present-day thickness we obtain the amount of compaction that occurred during any time interval.

\section{Parameter definition}

A key step in any numerical modelling is the choice of the most suitable and correct val- 
ues for each parameter and variable introduced in the calculations. Many of these values can be easily inferred from the abundant literature on the topic (e.g., Jaeger and Cook, 1979; Turcotte and Schubert, 1982; and references therein), while in some cases the choice of the numerical value is more difficult because the lack of geological, mechanical and geodynamic information does not allow a tight constraint of the parameter. In these cases, a more or less wide range of values has been tested.

\subsection{Elastic deformation}

Table I lists all the numerical values and ranges attributed to the parameters used in the program. However, in the following, only the most important parameters will be discussed.

As concerns elastic deformation, one of the most important parameters is the elastic thickness, $T_{e}$, which generally does not represent the entire lithosphere but only that part behaving elastically. Indeed, one of the major problems in defining this parameter is that the lithosphere is not perfectly elastic as assumed in the theory from which eqs. (2.1) to (2.5) are derived. In fact, the possible occurrence of hotter and/or less competent volumes within the lithosphere, diffuse creeping phenomena and the possible crust-mantle decoupling de facto strongly reduce the real elastic behaviour of the lithosphere. In order to account for these rheological heterogeneities within the lithosphere, a perfectly elastic but thinner lithosphere is commonly considered, that is an 'equivalent elastic thickness' is introduced in the calculations.

For the oceanic crust the elastic thickness is a function of age and roughly coincides with the isotherm of $600 \mathrm{C}^{\circ}$ (McNutt, 1988). In contrast, the continental lithosphere does not entirely depend on temperature and pressure conditions (Burov and Diament, 1995).

The thermal state of the continental lithosphere is one important factor among others that determines the value of the equivalent elastic thickness. Other factors are the state of the crust-mantle interface, the thickness and proportions of the mechanically competent crust and mantle and the local curvature of the plate that is directly dependent on the bending stresses (Burov and Diament, 1995).

Burov and Diament (1995) document that the continental lithosphere elastic thickness has a wide range of values between 5 and $110 \mathrm{~km}$. These authors also emphasise the occurrence of a bimodal distribution characterised by two peaks at $10-30 \mathrm{~km}$ and $70-90 \mathrm{~km}$, respectively.

Table I. List of parameters, their symbols and values used during numerical modelling. The values in the last column are those selected for the model application to the Late Anisian-Early Ladinian carbonate platforms of the Dolomites, Northern Italy. The selected values for the initial porosity and the compaction factor refer to the Bellerophon Formation (BEL) and the Werfen Formation (WER), respectively.

\begin{tabular}{lcccc}
\hline \hline Parameter & Symbol & Unit & Value or range & Selected value \\
\hline Young modulus & $E$ & $\mathrm{~Pa}$ & $10^{10}-10^{11}$ & $10^{10}$ \\
Poisson coefficient & $v$ & - & $0.22-0.25$ & 0.25 \\
Equivalent elastic thickness & $T_{e}$ & $\mathrm{~km}$ & $10-50$ & 21 \\
Mantle density & $\rho_{m}$ & $\mathrm{~kg} / \mathrm{m}^{3}$ & $3000-3500$ & 3500 \\
Replacement density & average of $\rho_{w^{-}} \rho_{p}$ & $\mathrm{~kg} / \mathrm{m}^{3}$ & 1100 & 1100 \\
Platform density & $\rho_{p}$ & $\mathrm{~kg} / \mathrm{m}^{3}$ & $1800-2200$ & 2200 \\
Initial porosity & $\phi_{0}$ & - & $0.3-0.7$ & BEL 0.6 \\
& & & & WER 0.5 \\
Compaction factor & $c$ & $\mathrm{~m}^{-1}$ & $2 \cdot 10^{-4}-7 \cdot 10^{-4}$ & BEL $5 \cdot 10^{-4}$ \\
& & & & WER 2.7 $10^{-4}$ \\
\hline
\end{tabular}



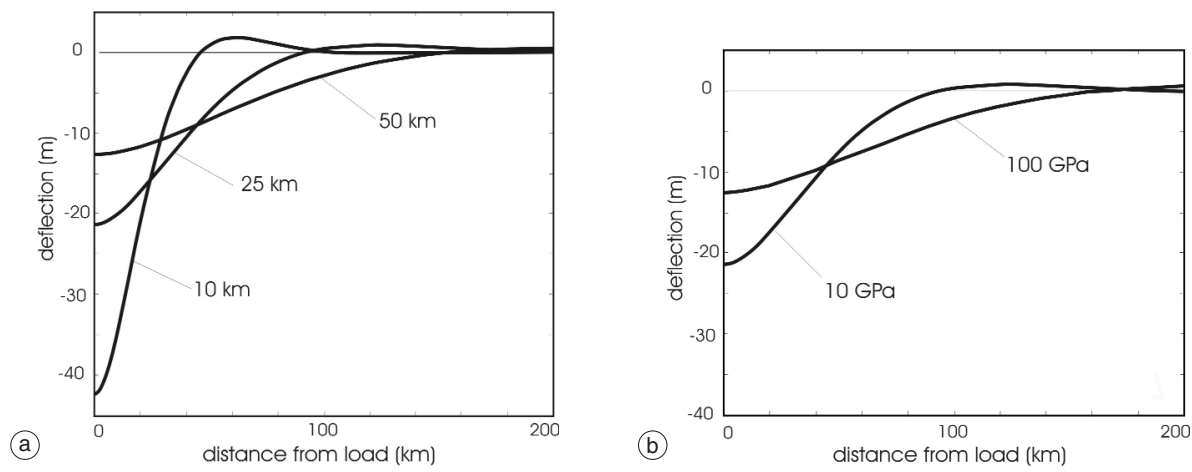

Fig. 2a,b. a) Influence of the equivalent elastic thickness $\left(T_{e}\right)$ on the deflection. The larger the value, the stronger the layer, the less important the maximum deflection. b) Influence of the Young Modulus on the deflection. Note the inverse proportionality between the Young modulus and the maximum deflection, the shift and the magnitude of the peripheral bulge.

Similarly, McNutt (1988) have compiled a database of elastic thickness values reported in the literature for the continental lithosphere under major mountain chains. The minimum value they collected is $15 \mathrm{~km}$, the maximum $30 \mathrm{~km}$.

Based on the gravity anomalies of the $\mathrm{Kr}-$ ishna-Godavari Basin in India and the inferred load induced by the sedimentary infill, Krishna et al. (1999) suggest that the best fitting value of the equivalent elastic thickness to explain the observed gravity anomalies is about $30 \mathrm{~km}$. Similar values were assumed to calculate the tectonic subsidence and the crustal flexure in the Chaco Basin, Bolivia (Coudert et al., 1994).

Accordingly, though the elastic thickness strongly depends on the broader and specific geodynamic conditions to be numerically simulated, as a first attempt for continental lithosphere we chose a range of values between 10 and 50 $\mathrm{km}$. The variability of $T_{e}$ has a twofold effect. Firstly, by decreasing the equivalent elastic thickness the maximum deflection increases almost proportionally and, secondly, the peripheral bulge moves closer to the central depression and becomes more pronounced (fig. 2a).

Also the Young modulus is inversely proportional to the maximum deflection, though its effects are less important because by varying $\mathrm{E}$ of one order of magnitude (from $10^{10}$ to $10^{11}$ $\mathrm{Pa}$ ), $w_{0}$ varies of about $\pm 25 \%$ (fig. $2 \mathrm{~b}$ ).
Another influencing parameter is the magnitude of the point load that is directly proportional to the maximum deflection (eq. (2.4)). On the other hand, this parameter is a function of i) the initial distribution and extension of the neritic conditions (i.e. the growing carbonate platform), ii) the amount of aggradation, iii) the amount of progradation and iv) the selected value for the density of platform rocks. All these factors will be further analysed and discussed in a later section where the numerical model is applied to real examples of carbonate platforms.

Elastic deformation is also influenced by the density contrast that determines the buoyant force induced by the replacement of the asthenosphere mantle rocks with less dense materials (fig. 1). Indeed, while the density of the replacement materials is close to unity, consisting for more than $95 \%$ of water, the replaced mantle rocks can range between 3000 and 3500 $\mathrm{kg} / \mathrm{m}^{3}$. Whatever the case, the final result is not strongly affected.

\subsection{Plastic deformation}

As concerns deformation associated with compaction, the most important parameters are the initial porosity and the compaction factor. Initial porosity, $\phi_{0}$, can strongly vary from more 
than $60 \%$ to less than $15 \%$ (Pryor, 1973; Campbell et al., 1974). Indeed, these extremely variable values of porosity are associated with strong variations in the possible amount of porosity reduction and therefore in compaction and the consequent subsidence. This parameter is particularly influential during the initial burial history of sediments (fig. 3a), though at depths greater than $5 \mathrm{~km}$, all curves tend to converge to a similar value.

The second important parameter playing a role during the compaction process is the so-
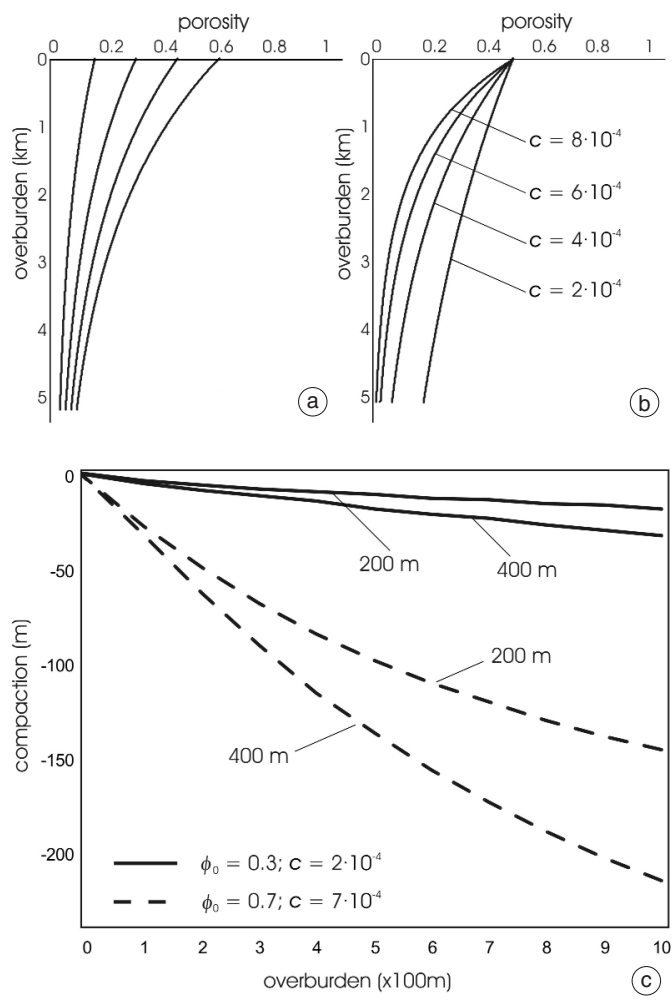

Fig. 3a-c. Reduction of porosity (i.e. compaction) associated to progressive burial: a) with variable initial porosity and constant compaction factor $\left.\left(c=4 \cdot 10^{-4}\right) ; b\right)$ with variable compaction factors $(c)$ and constant initial porosity $\left(\phi_{0}=0.5\right)$. c) Subsidence induced by compaction of a 'plastic' layer, for different initial thicknesses and material properties, as a function of the overburden. called compaction factor, $c$, in eq. (2.6) (fig. $3 b)$. In fact, although all $c$-curves have the common tendency to a progressive reduction in porosity, at great depths, say more than $5 \mathrm{~km}$, small and large values of $c$ differ up to almost $20 \%$. But even more important is the influence of this parameter during the burial evolution. For example, during the first $1000 \mathrm{~m}$ of burial, a compaction factor of $8 \cdot 10^{-4}$ induces about $30 \%$ of porosity reduction, while a value of $2 \cdot 10^{-4}$ is associated with only a $10 \%$ porosity reduction, that is of sedimentary compaction and thus of induced subsidence. This parameter strongly depends on the lithology of the sediments and especially on their texture characteristics.

A further influential factor as concerns the amount of induced subsidence is obviously the original thickness of the sedimentary unit undergoing compaction. Indeed, it is clear that whatever the compaction factor and the initial porosity are, the larger the original thickness the larger the final amount of induced subsidence (fig. 3c).

Again with reference to the plastic deformation and considering a simplified 3D truncatedconical shape for carbonate platforms, it is obvious that the amount of burial of the underlying sedimentary units varies with the position relative to the platform limits. Indeed, compaction is nil outside the platform toe of the slope and it is maximum inside the ring defining the shallow-water depositional area. Therefore, the slope angle directly influences the dimension of the annular gradient for the amount of compaction occurring in the sediments underlying the carbonate build up. Carbonate platforms in the Dolomites commonly range between $25^{\circ}$ and $45^{\circ}$.

\section{Applications to Triassic platforms of the Dolomites}

As mentioned in the introductory notes, the numerical model has been applied to some of the most spectacular and well-known examples of carbonate platforms in the world: the Dolomites of Northern Italy. Indeed, during the Middle and Upper Triassic, the whole region 
was characterised by several episodes of fast growing isolated carbonate buildups. The diverse generations of platforms generally differ in thickness, amount of aggradation and progradation and their relative rates. An extensive literature exists on the topic (see, for example, Bosellini et al., 1996 and references therein).

In order to test the numerical model, among the several generations of platforms that can be recognised in the Triassic succession of the Dolomites, we selected the so-called pre-volcanic Late Anisian to Early Ladinian platforms which are 400-800 m thick and show high aggradation rates and relatively simple pregrowth stratigraphic conditions.

The relatively short time interval (i.e. Late Anisian-Early Ladinian) of platform growth, lasting probably less than $2 \mathrm{Myr}$ (Gianolla et al., 1998), assures that the assumption of a geologically restricted temporal time window is satisfied and therefore the viscous contribution to deformation can be neglected (e.g. Walcott, 1970; Beaumont, 1978).

Due to the strong influence of the equivalent elastic thickness in the numerical modelling, we paid special attention to the selection of this parameter. As previously discussed, the elastic thickness of the continental lithosphere depends on numerous factors. Burov and Diament (1995) showed that the thermal state of the lithosphere, the crust-mantle interface, the thickness and proportions of the mechanically competent crust and mantle and the local curvature of the plate, which is directly related to the bending stress, are all crucial properties in defining the equivalent elastic thickness of a region. Nevertheless, following Burov and Diament (1995), an estimate of the equivalent elastic thickness of the Dolomite region during Middle Triassic can be attempted. Based on the available data for the Hercynian orogeny that affected the area during the Devonian-Carboniferous period, the thermal age of the lithosphere at the time of platform growth was about 100 Myr (Del Moro et al., 1980; Zanferrari and Poli, 1992). Based on this age and if we assume a realistic value for the Triassic crustal thickness of about $20-25 \mathrm{~km}$ as an average, following Burov and Diament (1995) it is possible to estimate a $T_{e}$ between 20 and $22 \mathrm{~km}$. As a mean value, we selected $21 \mathrm{~km}$ for our calculations, bearing in mind a $\pm 5 \%$ of variability induced by this parameter.

The next step was quantifying the load produced by each carbonate platform and its area of influence. It is therefore necessary to identify and locate the several buildups belonging to this Middle Triassic generation of platforms and to define the dimensions of each carbonate body. Based on literature data (Gianolla et al., 1998, and references therein), published geological maps (Leonardi et al., 1968; Caputo et al., 1999) and available unpublished data (M. Stefani and P. Gianolla, pers. comm.), we inferred the possible initial dimensions of the different platforms, the amount of aggradation and that of progradation which characterised the growth of the several Late Anisian-Early Ladinian carbonate bodies. Due to the locally deep erosion and the tectonic deformation that occurred in the Dolomites, the reconstruction of the geometric parameters (thickness and lateral extension) has sometimes been inferred. However, due to the relatively

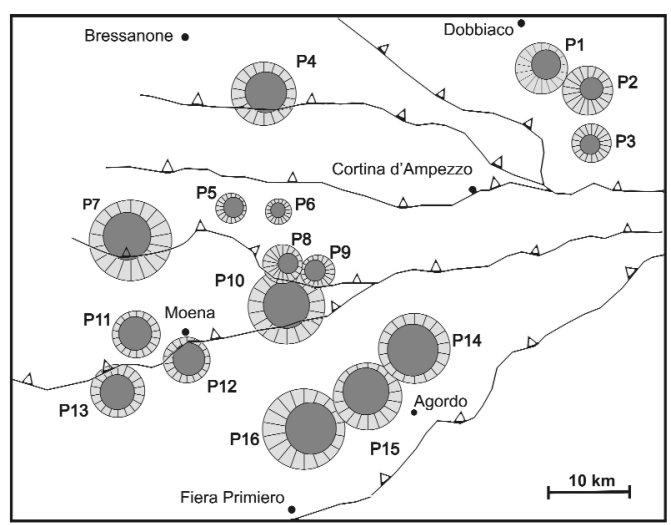

Fig. 4. The present-day distribution of the Late Anisian-Early Ladinian carbonate platforms considered for modelling in the present note. The filled circles tentatively represent the size of the initial nuclei, while the external circles (radial pattern) are proportional to the final size (maximum progradation). The general geometry of the bodies is obviously highly simplified. Platform labels indicated in figure correspond to table II. Major thrusts affecting the region are also represented. 
Table II. List of parameters used for modelling the 16 carbonate platforms. Label: platform label used in figs. 6 and 7; $a$ - initial platform radius (m); b - final platform radius (m); $\mathrm{c}$ - final platform thickness (m); $\mathrm{d}$ - present-day thickness of the Bellerophon Formation underlying the platform $(\mathrm{m})$; e - present-day thickness of the Werfen Formation underlying the platform $(\mathrm{m})$; $\mathrm{f}$ - present-day thickness of the post-Werfen to pre-Late Anisian succession; $\mathrm{g}$ - estimated maximum overburden on top of the Werfen Formation.

\begin{tabular}{ccccccccc}
\hline \hline Label & Name & $\mathrm{a}$ & $\mathrm{b}$ & $\mathrm{c}$ & $\mathrm{d}$ & $\mathrm{e}$ & $\mathrm{f}$ & $\mathrm{g}$ \\
\hline P1 & Croda dei Baranci & 1800 & 3250 & 400 & 260 & 420 & 400 & 4220 \\
P2 & Tre Scarperi & 1500 & 3100 & 400 & 310 & 420 & 400 & 4310 \\
P3 & Cadini di Misurina & 1250 & 2500 & 400 & 310 & 410 & 400 & 4240 \\
P4 & Putia-Sass Rigai & 2600 & 4000 & 650 & 140 & 200 & 150 & 2300 \\
P5 & Sassolungo & 1200 & 1950 & 450 & 215 & 140 & 100 & 1750 \\
P6 & Sella & 900 & 1600 & 450 & 220 & 80 & 100 & 1780 \\
P7 & Sciliar-Catinaccio & 3000 & 5200 & 500 & 150 & 290 & 130 & 1780 \\
P8 & Gran Vernel & 1250 & 2500 & 750 & 230 & 170 & 150 & 1700 \\
P9 & Marmolada & 1300 & 2150 & 750 & 235 & 160 & 150 & 1880 \\
P10 & Ombretta & 3000 & 4800 & 800 & 220 & 200 & 150 & 1750 \\
P11 & Latemar & 2400 & 3000 & 750 & 180 & 320 & 150 & 1650 \\
P12 & Viezzena & 2000 & 2950 & 750 & 210 & 310 & 150 & 1650 \\
P13 & Agnello & 2100 & 3400 & 750 & 145 & 340 & 150 & 1600 \\
P14 & Civetta & 3200 & 4500 & 500 & 205 & 220 & 500 & 2840 \\
P15 & San Lucano & 2900 & 4300 & 500 & 190 & 250 & 500 & 2540 \\
P16 & San Martino & 3200 & 5200 & 600 & 160 & 300 & 450 & 2330 \\
\hline
\end{tabular}

strong influence of these parameters on the calculated subsidence, we attempted a conservative interpretation keeping the inferred dimensions to the minimum values. Accordingly, in fig. 4, the nuclei of the considered platforms are highly simplified and represented as filled circles whose dimensions are roughly indicative of the possible initial size.

We emphasise that in some cases the considered platforms, whose corresponding values are reported in table II, merged during their growth due to convergent progradation thus forming a unique larger carbonate body. This is certainly the case, for example, of the Civetta-San LucanoSan Martino platforms (P14-P15-P16 in fig. 5; Bosellini et al., 1996) and the Gran Vernel-Marmolada platforms (P8-P9 in fig. 5; Stefani and Caputo, 1998). However, in terms of produced load and thus of induced subsidence, our separate and simplified carbonate bodies are roughly equivalent to more realistic platform shapes.

With respect to the plastic contribution to deformation, an important aspect of numerical modelling is the selection of the parameters characterising the underlying sedimentary units that are supposed to have undergone compaction

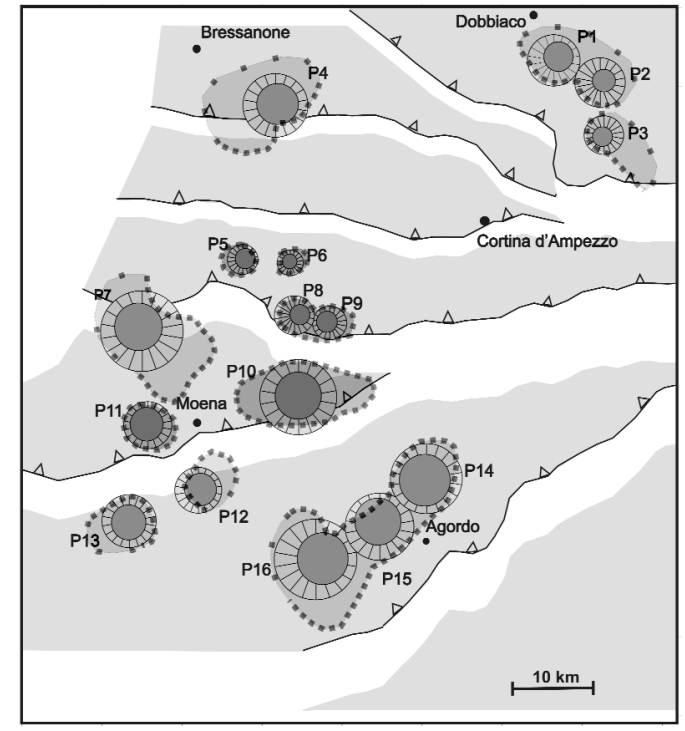

Fig. 5. Tentative palinspastic reconstruction of the Dolomites and assumed location and distribution of the carbonate platforms during Late Anisian-Early Ladinian. Platform labels correspond to table II. The dotted pattern shows the outer limit of the coalesced platforms. 
during the growth of the carbonate buildups. First of all, we have to define which formations could have undergone some compaction. Indeed, the pre-Late Anisian stratigraphy of the Dolomites shows that on top of the Palaeozoic metamorphic basement the sedimentary units of some interest for our model due to their thickness, lithology and area distribution are the Val Gardena Sandstone (Middle Permian), the Bellerophon Formation (Late Permian) and the Werfen Formation (Schythian). Other sedimentary units also exist but they mainly consist of carbonate layers, like for example the Contrin Formation, or they are coarse-grained like the Sesto and Ponte Gardena Conglomerates. In the former case, diagenesis usually occurs soon after deposition thus impeding any important compaction during burial; while in the latter case, the compaction factor is generally extremely low and so not influential in our calculations. Moreover, as concerns the Val Gardena Sandstone, the time elapsed between sedimentation and the growth of the platforms investigated in this paper was probably sufficiently long to allow an almost complete diagenesis. Therefore their possible contribution to subsidence as induced by compaction is likely to be negligible.

According to geological and stratigraphic data (e.g., Bosellini, 1968), the present-day thickness of the Bellerophon and Werfen formations have been inferred in correspondence with the several carbonate platforms (table II).

However, in order to estimate the amount of compaction suffered by these two sedimentary formations during the growth of the Late AnisianEarly Ladinian platform generation and the consequent amount of induced subsidence, it is also necessary to know their pre-platform burial history and particularly the thickness of the stratigraphic succession already overlying the Bellerophon and Werfen units just before the Late Anisian. Therefore, the amount of the postScythian to pre-Late Anisian overburden existing in correspondence with each considered platform has been also inferred (Assereto et al., 1977; Masetti and Trombetta, 1998; Gianolla et al., 1998) and used during numerical modelling (table II).

There is no way to directly measure the initial porosity $\left(\phi_{0}\right)$ and the compaction factor $(c)$ of the two above-mentioned sedimentary units.
However, by considering comparable presentday sediments (e.g., Campbell et al., 1974; Sclater and Christie, 1980) these parameters have been tentatively assumed for the Bellerophon and Werfen units. The selected values of initial porosity are 0.6 and 0.5 , respectively, while those of the compaction factor are $5 \cdot 10^{-4}$ and $2.7 \cdot 10^{-4}$, respectively (table I).

Furthermore, in order to correctly calculate the amount of subsidence induced by compaction, the total burial overlying the PermoScythian formations just before the occurrence of the Oligocene-Quaternary widespread erosion must be estimated (table II). Accordingly, following the procedure proposed by Sclater and Christie (1980), we calculated the thickness of the two modelled sedimentary units just before the growth of the Late Anisian-Early Ladinian carbonate platforms. These values have been used as reference values for the calculation of the induced compaction (viz. subsidence).

\section{Subsidence map}

It is clear that the present-day distribution of the investigated platforms does not correspond to the original pattern. It is well known that mainly during Cainozoic times the Dolomites suffered considerable deformation (e.g., Doglio- ni and Bosellini, 1987). However, in order to account for the large-scale effects of the elastic deformation induced by each single carbonate body, we had to perform a palinspastic restoration to obtain the original distribution. We are well aware of the complex tectonic evolution that affected the region both in terms of intensity, distribution and kinematics of the different deformational events recognised in the area (e.g., Caputo, 1996). Nevertheless, as a first approximation we can assume that the bulk of shortening which occurred in the Dolomites has a mean N-S direction (Doglioni, 1987; Doglioni and Bosellini, 1987; Castellarin et al., 1992; Caputo, 1997; Caputo et al., 1999). Accordingly, we firstly identified the major thrusts affecting the region and the amount of shortening they caused and then we reconstructed a simplified palaeogeographic map of Middle Triassic times (fig. 5) slightly modifying that proposed by Bosellini (1996). 
Based on this palinspastic restoration and the consequent re-location of the carbonate platforms we thus performed the calculations of the induced elastic deformation for the broader Dolomite region.

As a first step, we calculated the subsidence induced by a single platform at different stages of the whole process. Figure 6a-d shows an example of subsidence evolution in four time steps, relative to the Sciliar-Catinaccio platform (P7). Both local and regional contributions are evident, while the gradient in between the two patterns is an effect of the prograding slope.

The same calculations have been performed for all investigated platforms and all contributions have been summed up to generate the total subsidence map represented in fig. 7. This map represents the regional distribution of the amount of subsidence induced by the growth of the Late Anisian to Early Ladinian carbonate buildups. Also in this case, both local and regional patterns are evident.
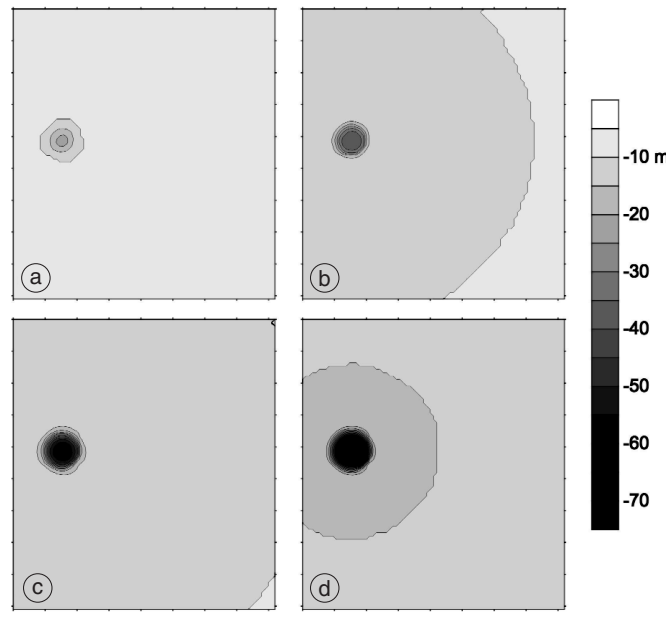

Fig. 6a-d. Four time-steps map (a to d) representing the progressive subsidence induced by the growth of a single pre-volcanic platform: the example corresponds to the Sciliar-Catinaccio (P7 in figs. 4 and 5 and in table II). The contour lines of the induced subsidence are in meters (see grey scale).

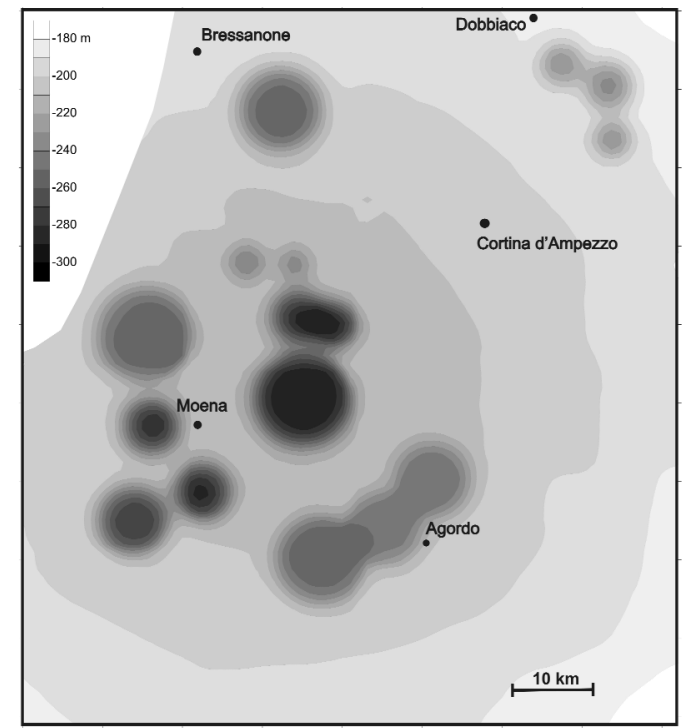

Fig. 7. Map of the calculated subsidence induced by the growth of all Late Anisian-Early Ladinian carbonate platforms. Both elastic (regional) and plastic (local) contributions are evident and can be easily quantified. The round geometry of the local contributions is due to the simplified shape of the carbonate bodies assumed in the model. The contour lines of induced subsidence are in meters (see grey scale). The maximum regionally induced subsidence is concentrated in the Central Dolomites and amounts to about $220 \mathrm{~m}$, while local contributions range between 40 and $90 \mathrm{~m}$.

\section{Concluding remarks}

Due to the uncertainties in the selection of some of the parameters used in the numerical model and according to their more or less important influence in the calculations as discussed in a former section of the paper, it is clear that our final results should be considered as a first order approximation of the investigated natural phenomenon. Nevertheless, these results clearly show that the subsidence induced by the growth of the Late Anisian-Early Ladinian carbonate platforms in the Dolomites gave an important contribution for generating the accommodation space required for these thick successions of shallow-water sediments. 
Based on the distribution and the diverse thickness values of the platforms (table II), we can tentatively reconstruct the map of the total subsidence occurred in the Dolomites during the Middle Triassic that caused the necessary accommodation space (fig. 8a). According to our
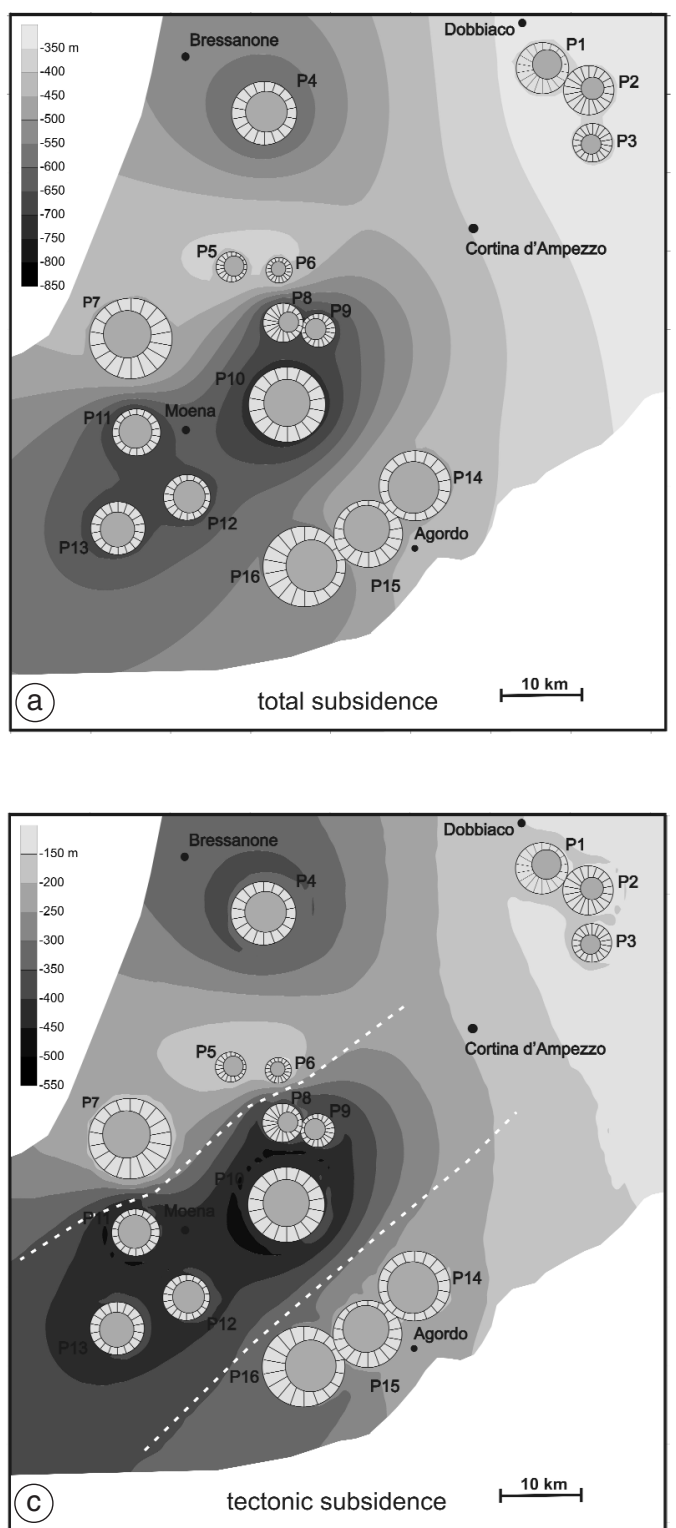

calculations, the subsidence induced by the growth of carbonate platforms gives an important contribution as high as $20 \%$ to $40 \%$ of the total amount of subsidence. Consequently, this contribution should not be disregarded especially when dealing with stratigraphic, palaeogeo-

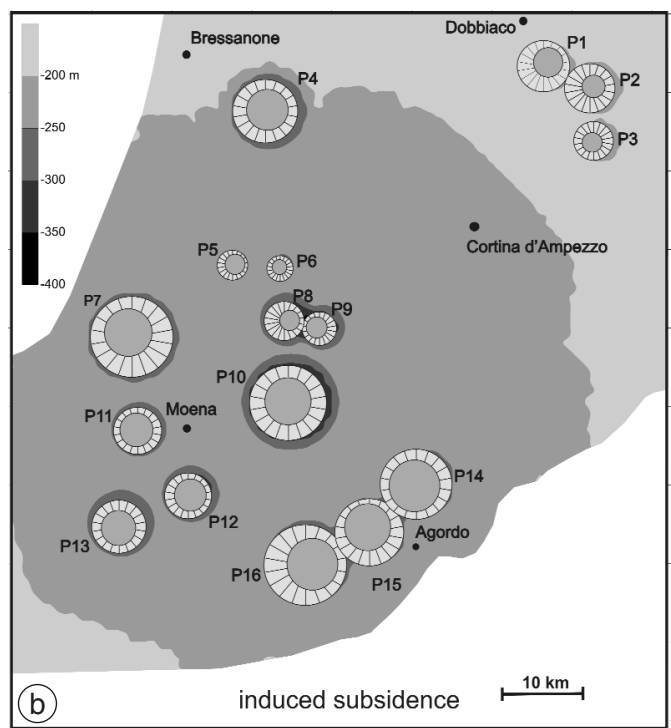

Fig. 8a-c. a) The estimated pattern of the total subsidence in the Dolomites during Middle Triassic as inferred from the thickness of the carbonate bodies (table II). b) Map of the subsidence induced by the growth of the platforms (simplified from fig. 7). c) Pattern of the tectonic subsidence obtained from the former two maps and likely induced by a far field extensional stress field. The map emphasises the existence of a NE-SW oriented graben affecting the Central Dolomites. Dashed lines represent the two major border faults (or fault systems). Contours lines are in metres in all three maps (see corresponding grey scales). 
graphic and geodynamic reconstructions of the Dolomites. Moreover, this local overload by carbonate platforms induces a positive feedback because any increased subsidence induces further growth and consequently a larger load onto the lithosphere. The quantification for the first time of this contribution is a major result of this paper.

Obviously a remote stress field, whose origin is probably associated with a process of lithospheric stretching, induced the remaining $60-80 \%$ of subsidence. By combining the map of the total subsidence (fig. 8a) with that of the induced subsidence (fig. 8b) it is possible to obtain a map of the tectonic subsidence (fig. $8 \mathrm{c})$. According to fig. 8c, the Central Dolomites are characterised by a $20 \mathrm{~km}$ wide NESW trending graben where the two border faults (or fault systems) show a vertical displacement of about $200 \mathrm{~m}$. It is well known that immediately after the growth of the Late Anisian-Middle Ladinian carbonate platforms, the Central Dolomites were affected by a short but intense volcanic event. It is noteworthy that the two major magmatic bodies (Predazzo and Monzoni) documented in the area, partially intruding the platforms and associated with volcanic edifices, are located exactly along the southern border of the graben. It is likely that the rising of the magma and the emplacement of the plutons were facilitated by a crustal scale extensional structure.

Further geologic and palaeogeographic implications of this study also regard the depth of the surrounding and/or adjacent basins. In fact, if a platform subsides solidly with the adjacent basin, the water-depth of this basin grossly corresponds to the thickness difference between platform carbonates and basin sediments. In contrast, if a platform subsides independently the former equation is not valid (fig. 9a,b). The results obtained from the application of the proposed numerical model to the Middle Triassic evolution of the Dolomites certainly gave a contribution to unravel this problem and to choose between the two hypotheses. Indeed, the approach followed allows the differential subsidence between the areas with a direct overload induced by the platform and the adjacent basin to be quantified.

According to the results presented in this paper, the differential subsidence induced by the
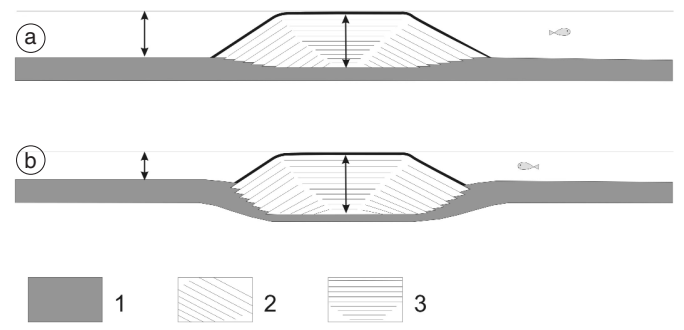

Fig. 9a,b. Regional (a) and local (b) subsidence of a carbonate platform (Bosellini, 1984). In the former case, the water depth of the basin roughly corresponds to the thickness of the carbonate platform. In the latter case, with a similar amount of aggradation, the adjacent basin is much shallower. 1: deep-water deposits; 2: platform slope deposits; 3: internal platform deposits.

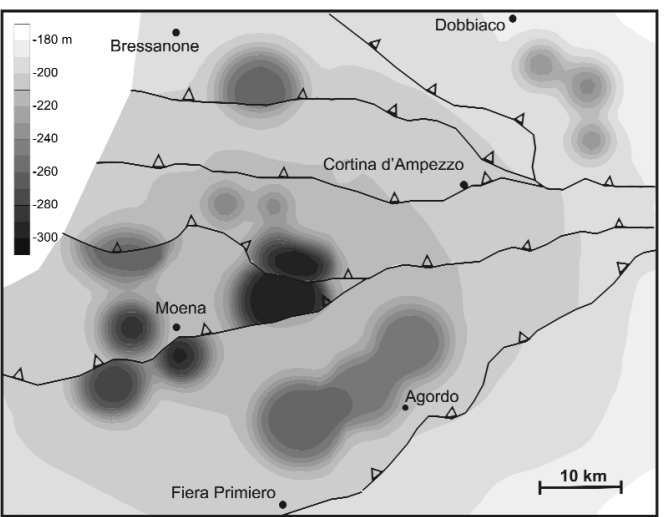

Fig. 10. Map of the calculated subsidence occurred during Middle Triassic and reduced to its present-day distribution after considering the Tertiary contraction.

400-800 m thick overlying platforms has a magnitude of some tens of meters, while its gradient is distributed within the progradation zone, that is between the nucleus of the platform, where compaction is maximum, and the toe of the slope, where the compaction is nil. It is thus clear that the Middle Triassic subsidence induced by compaction generated a 'very local' effect. Therefore, the latter hypothesis for the 
occurrence of an 'independent' subsidence (fig. $9 \mathrm{~b}$ ) is supported by our numerical modelling. However, because the differential subsidence we calculated is distributed along a distance of several hundreds of metres to some kilometres, corresponding to the dimension of a prograding slope, its influence in terms of thickness variations and original geometry of the sedimentary bodies is probably not detectable with geological means.

These results can be easily extended to other generations of carbonate platforms of the Dolomites as well as elsewhere in the stratigraphic record.

A second major outcome of this research is the reconstruction of the present-day distribution of the subsidence induced by the local overload, after re-considering the Tertiary shortening that affected the region (fig. 10). With the exception of the local 'troughs' directly caused by, and underlying the platforms, lateral variations in the amount of induced subsidence is generally limited, being about $50 \mathrm{~m}$ across the whole Dolomite region. Consequently, also in this case, even specific and dedicated geological investigations will probably not disclose any significant information in the stratigraphic record documenting these small variations relative to the depth of the basin surrounding the platforms or concerning the thickness of the basinal deposits.

\section{Acknowledgements}

We thank to M.R. Gallipoli, M. Mucciarelli, D. Albarello for discussions on the numerical modelling and to M. Stefani and P. Gianolla for supporting unpublished data about the Triassic platforms of the Dolomites.

\section{REFERENCES}

Assereto, R., C. Brusca, M. Gaetani and F. Jadoul (1977): The $\mathrm{Pb}-\mathrm{Zn}$ mineralization in the Triassic of the Dolomites. Geological history and genetic interpretations, L'Industria Mineraria, XXVIII, 1-15.

AтHY, L.F. (1930): Density, porosity and compaction of sedimentary rocks, Bull. Am. Ass. Petrol. Geol., 14, 1-24.

Baldwin, B. and C.O. Butler (1985): Compaction curves, Bull. Am. Ass. Petrol. Geol., 69, 622-626.

BEAUMONT, C. (1978): The evolution of sedimentary basins on a viscoelastic lithosphere: theory and examples, Geophys. J. R. Astron. Soc., 55, 471-497.

Bosellini, A. (1968): Paleogeologia pre-anisica delle Dolomiti Centro-Settentrionali, Atti Acc. Naz. Lincei, CCCLXV, 1-33.

Bosellini, A. (1984): Progradation geometries of carbonate platforms: example from the Triassic of the Dolomites, Northern Italy, Sedimentology, 31, 1-24.

Bosellini, A. (1996): Geologia delle Dolomiti (Ed. Athesia, Bolzano), pp. 192.

Bosellini, A., C. Neri and M. Stefani (1996): Geologia delle Dolomiti. Introduzione geologica. Guida all'escursione generale, in 78 a Riunione Estiva Soc. Geol. Italiana, 16-18 Settembre, San Cassiano, pp. 120.

Burov, B. and M. Diament (1995): The effective elastic thickness $\left(T_{e}\right)$ of the continental lithosphere: what does it really mean?, J. Geophys. Res., 100, 3,905-3,927.

CAMPBell, R., F. CORTs et al. (1974): Well evaluation Conference - North Sea, Schlumberger, France, pp. 171.

CAputo, R. (1996): The polyphase tectonics of Eastern Dolomites, Italy, Mem. Sci. Geol., 48, 93-106.

CAPUTO, R. (1997): The puzzling regmatic system of Eastern Dolomites, Mem. Sci. Geol., 49, 1-10.

Caputo, R., M. Stefani and G. Dal Piaz (1999): Contractional and transcurrent tectonics in the Marmolada Group (Dolomites, Italy), Mem. Sci. Geol., 51 (1), 63-77.

Castellarin, A., L. Cantelli, A.M. Fesce, J.L. Mercier, V. Picotti, G.A. Pini, G. Prosser and L. Selli (1992): Alpine compressional tectonics in the Southern Alps. Relationships with the N-Apennines, Ann. Tectonicae, 6 (1), 62-94.

Coudert, L., M. Frappa, C. Viguier and R. Arias (1994): Tectonic subsidence and crustal flexure in the Neogene Chaco basin of Bolivia, Tectonophysics, 243, 277-292.

Del Moro, A., F.P. SASSi and G. ZirPoli (1980): Preliminary results on the radiometric age of the Hercynian metamorphism in the South-Alpine basement of the Eastern Alps, N. Jb. Geol. Paläont. Mh., 707-718.

Doglioni, C. (1987): Tectonics of the Dolomites (Southern Alps-Northern Italy). J. Struct. Geol., 9 (2) 181-193.

Doglioni, C. and A. Bosellini (1987): Eoalpine and mesoalpine tectonics in the Southern Alps, Geol. Rund., 76, 735-754.

Gianolla, P., V. De Zanche and P. Mietto (1998): Triassic sequence stratigraphy in the Southern Alps (Northern Italy): definition of sequences and basin evolution, inMesozoic and Cenozoic Sequence Stratigraphy of European Basins, SEPM Spec. Publ. 60, 719-747.

Haq, B.U., J. HardenPol, P.R. Vail, R.C. Wright, L.E. Stover, G. Baum, T. Loutit, A. Gombos, T. Davies, C. Pflum, K. Romine, H. Posamentier and R. Gian Du Chener (1987): Mesozoic-Cenozoic Cycle Chart, Version 3.1A.

JAEGER, J.C. and N.G.W. CoOK (1979): Fundamentals of Rock Mechanics (Chapman and Hall, London), 3rd edition, pp. 593.

KARNER, G.D. and A.B. WATTS (1983): Gravity anomaly and flexure of the lithosphere at mountain ranges, $J$. Geophys. Res., 88, 10,449-10,477.

Krishna, M.R., S. ChAND and C. Subrahmanyam (1999): Gravity anomalies, sediment loading and lithospheric flexure associated with the Krishna-Godavarin Basin, eastern continental margin of India, Earth Planet. Sci. 
Lett., 175, 223-232.

Leonard, P. (1968): Le Dolomiti. Geologia dei Monti tra Isarco e Piave (Ed. Manfrini, Rovereto), 2 vols.

LOWRIE, W. (1997): Introductory geophysics (Cambridge University Press, London), pp. 354.

MASETti, D. and G.L. TromBetTA (1998): L'eredità anisica nella nascita ed evoluzione delle piattaforme medio-triassiche delle Dolomiti occidentali, Mem. Sci. Geol., 50, 213-237.

McKenZIE, D.P. (1978): Some remarks on the development of sedimentary basins, Earth Planet. Sci. Lett., 40, 25-32.

McNuTT, M.K. (1988): Variations of elastic Plate Thickness at Continental Thrust Belts, J. Geophys. Res., 93 , $8,825-8,838$.

PRYOR, W.A. (1973): Permeability-porosity patterns and variations in some Holocene sand bodies, Am. Ass. Petrol. Geol. Bull., 57, 162-189.

Ranalli, G. (1987): Rheology of the Earth. Deformation and Flow Processes in Geophysics and Geodynamics (Allen \& Unwin), pp. 366.

RIEKE, H.R. and G.V. ChILINGARIAN (Editors) (1974): Compaction of Argillaceous Sediments, Dev. Sedimentol. 16, pp. 424.

RuBY, W.W. and M.K. HubERT (1960): Role of fluid pressure in mechanics overthrust faulting, II. Overthrust belt in geosynclinal area of Western Wyoming in light of fluidpressure hypothesis, Bull. Geol. Soc. Am., 70, 167-206.

Sclater, J.G. and P.A.F. Christie (1980): Continental stretching: an explanation of post mid-Cretaceous sub- sidence of the central North Sea Basin, J. Geophys. Res., 85, 3711-3739.

SClATER, J.C., R.N. ANDERSON and M.L. BeLl (1971): Elevation of ridges and evolution of the Central Eastern Pacific, J. Geophy. Res., 76, 7,888-7,915.

SteFAni, M. and R. CAPUTO (1998): Stratigrafia triassica e tettonica Alpina nel Gruppo Marmolada-Costabella (Dolomiti Centrali), Mem. Soc. Geol. Italiana, 53, 263-293.

Timoshenko, S. and J.N. Goodier (1951): Theory of Elasticity (McGraw-Hill, New York), pp. 506.

TurcotTE, D.L. and G. Schubert (1982): Geodynamics Applications of Continuum Physics to Geological Problems (J. Wiley and Sons, New York), pp. 450

WALCOTT, R.I. (1970): Flexural rigidity, thickness and viscosity of the lithosphere, J. Geophys. Res., 75, 3,9413,954

WANG, W.H. (2001): Lithospheric flexure under a critically tapered mountain belt: a new technique to study the evolution of the Tertiary Taiwan orogeny, Earth Planet. Sci. Lett., 192, 571-581.

ZANFERRARI, A. and M.E. POLI (1992): Il basamento sudalpino orientale: stratigrafia, tettonica varisica e alpina, rapporti copertura-basamento, Studi Geologici Camerti, 1992/2 (spec. vol.), 299-302.

(received October 6, 2003; accepted March 4, 2004) 